\title{
Reflections of a Mathematics Teacher Educator: Considerations for Mathematicians Who Teach Teachers
}

\section{Christina Eubanks-Turner}

Early on in my career, I knew I wanted to be involved in training mathematics teachers. In graduate school, as I worked toward a doctorate in mathematics, focusing on the study of commutative algebra, I always had a passion for using my knowledge and skills to impact K-12 education. I was fortunate to study in a mathematics department that allowed interested graduate students to be involved with professional development programs to train current teachers and teach mathematics courses for future teachers. While that was over fifteen years ago, I still have a desire to be a change agent in education and look for meaningful ways to work with current and future mathematics teachers.

Recent developments in K-12 mathematics education, such as the implementation of the Common Core standards and the call for the inclusion of equitable mathematics teaching practices (NCTM, 2014), require mathematics teachers at every level to reflect on, and in many cases alter, their teaching practice. To keep abreast of these needs, mathematics teacher educators have begun to "define, research, and refine the characteristics of effective teachers of mathematics" (AMTE, 2017, p. xvi). As there is

Christina Eubanks-Turner is an associate professor of mathematics at Loyola Marymount University. Her email address is ceturner@1mu. edu.

Communicated by Notices Associate Editor William McCallum.

For permission to reprint this article, please contact: reprint-permission aams.org.

DOI: https://dx.doi.org/10.1090/noti2028 a well-established knowledge base on K-12 mathematics teacher education (Sanchez, 2011), there is a growing need for research on the knowledge that mathematics teacher educators need in order to prepare mathematics teachers (Jaworski \& Huang, 2014).

Not only does mathematics teaching require knowledge of mathematics, but also a knowledge of teaching and learning. The MET II report states that "the mathematical knowledge needed by teachers at all levels is substantial yet quite different from that required in other mathematical professions" (MET, 2012). An example given by the Elementary Math Project (2019) states, "people with common knowledge of mathematics can divide accurately and solve division word problems, while teachers with specialized content knowledge possess common knowledge of division as well as the knowledge to explain why division procedures work, how division can be interpreted using equal sharing, measurement and missing factor interpretations, how remainders can be interpreted, and under what circumstances quotients are smaller, equal to, or larger than the dividend." This knowledge, called Mathematical Knowledge for Teaching, is a specialized content knowledge that is specific to teaching mathematics (Ball et al., 2008). Although there have been national recommendations that mathematics content courses for teachers include content that develops mathematical knowledge for teaching, there has been minimal consideration given to the development of future teachers' mathematical knowledge for teaching in 
mathematics content courses for teachers (Hart, Oesterle, \& Swars, 2013). This realization has garnered attention from both the mathematics and mathematics education communities. Recently, the Association for Mathematics Teacher Educators released Standards for Preparing Teachers of Mathematics (AMTE, 2017), which gives a comprehensive guide for various stakeholders of the national vision for teacher preparation, including standards for mathematicians who teach future teachers.

Researchers have begun to investigate the knowledge that educators of current and future K-12 teachers (Mathematics Teacher Educators) need to teach teachers (Zopf, 2010; Masingila, Olanoff, \& Kimani, 2017). Similar to the conceptualization of Mathematical Knowledge for Teaching, Zopf defined the Mathematical Knowledge for Teaching Teachers as "the mathematical knowledge used by mathematics teacher educators in the work of teaching mathematics to teachers" (p. 11). Just as K-12 teachers utilize specialized mathematical knowledge to teach children, mathematics teacher educators use specialized knowledge to teach teachers, which differs in some aspects from the knowledge needed to teach children. For instance, mathematics teacher educators teach adults, not children, and so this requires mathematics teacher educators to help teachers relearn mathematics (Superfine et al., forthcoming).

While mathematicians are trained to deeply understand the complexities of mathematics in content courses for teachers, they typically receive no training or development to be an educator (Bass, 1997). The MET II recommends mathematics and statistics departments offer instructors support for professional development to increase expertise in teaching teachers (MET II, 2012). As a mathematician who has worked in teacher education since 2005, some of my mathematical knowledge for teaching teachers came from my experiences teaching current teachers in graduate courses and professional development and teaching future elementary and secondary teachers. Additionally, my study of educational research, collaborating with math educators to better understand teacher education, and many years of presenting and participating in various workshops, conferences, and seminars have enhanced my mathematical knowledge for teaching teachers. Below I give recommendations mathematicians should consider when they teach mathematics courses for teachers to support the development of teachers' mathematical knowledge for teaching. These recommendations are for mathematics teacher educators who teach current and/or future teachers.

\section{1.}

Teachers need to see clear connections between the mathematics that they are learning and the mathematics that they will teach. This recommendation is especially relevant for those teaching secondary school teachers. As mathematics teacher educators we should strive to help teachers see how most, if not all, topics in mathematics content courses for teachers connect to the mathematics they are expected to teach, and if this is not possible, we should carefully consider the purpose of those topics in these courses. The latter does not imply that mathematics teacher educators should teach K-12 math only: as the MET II states, "coursework for prospective teachers should examine the mathematics they will teach in-depth, from a teacher's perspective" (p. 17), but there should be clear, unambiguous discussions about how the coursework they are learning relates to the elementary or secondary concepts they will teach. Among other connections, teachers need to see a progression of how elementary or secondary concepts are concrete representations of concepts they are learning in their content courses, which gives teachers an understanding of the vertical alignment of the concept, deepening their content knowledge and illustrating the mathematical relevance of these topics.

As an example, I regularly teach an abstract algebra course for secondary teachers, where I explain in explicit detail and work with teachers through examples and exercises to demonstrate how the zero product property connects to the abstract algebra concept of integral domains. This example serves as a relevant connection for secondary teachers, as the zero product property is viewed by many secondary teachers as an important concept related to solving for roots of polynomials, which is a focus of secondary algebra. Also, mathematics teacher educators should make sure teachers understand how the knowledge they are gaining affects their understanding and teaching of the mathematics they teach. The latter requires mathematics teacher educators to have some knowledge of the mathematics currently being taught in elementary and secondary schools.

\section{2.}

Mathematics teacher educators should ensure that teachers experience highly effective teaching practices in their mathematics content courses. Also, mathematics teacher educators should be transparent about instructional practices they are utilizing while teaching these courses so teachers can understand why they are modeling a particular practice and how it impacts learning. For mathematicians who are just starting as mathematics teacher educators and want to find where to begin searching for resources on research-based effective mathematical teaching practices, I would suggest they start by asking a colleague who has expertise in education. Various professional societies that focus on teaching mathematics at various levels have resources related to best practices in mathematics teaching (NCTM, 2014; MAA, 2017; AMTE, 2017). Note that while many resources focus on $\mathrm{K}-12$ mathematics teaching, many practices can be used or modified for use in higher education.

Also, if mathematics teacher educators are working with mathematics teachers who are currently in the classroom, 
mathematics teacher educators can view their work with those teachers as a partnership and learn effective pedagogical practices from them. Some instructional strategies I routinely use in all my courses and explicitly model in my courses for teachers are to introduce a mathematical concept by having teachers solve and discuss low floor/high ceiling tasks, that is, tasks that all students can access but that can extend to high levels (Boaler, 2015); orchestrate and sequence productive mathematical discussion in class (Smith et al., 2011); and have students engage in paired board work to solve problems (MAA, 2017).

\section{3.}

Beginning teachers need opportunities to rehearse mathematics teaching in a low-stakes environment. Not only should teachers have rehearsals in their education courses (McDonald et al., 2013), there is still a need for rehearsals in their mathematical content courses, where teachers will get the opportunity to not only teach $\mathrm{K}-12$ mathematics that connects to the mathematics they are learning, but also teach the mathematics they are being taught in their mathematical content courses. Rehearsing mathematics would allow teachers the opportunity to demonstrate their knowledge in practice. Specifically, mathematics teacher educators should have students engage in approximations of practice (Grossman et al., 2009). Approximations of practice allow beginning teachers to simulate different components of teaching. These approximations of practice should not replace real teaching experiences, but allow beginning teachers to act out teaching in a safe environment where they can get feedback from their mathematics teacher educator and peers (Grossman et al., 2009).

McDonald, Kazemi, and Kavanagh (2013) give a learning cycle related to approximations of practice to enact core teaching practices. In this cycle, teachers learn a particular practice from their mathematics teacher educator. Then the teacher prepares and rehearses the practice with their mathematics teacher educator and peers. After, the teacher enacts the practice with real students, which is then followed by an analysis of the enactment. Approximations of practice I have used in my content courses for teachers include teachers crafting questions that could be posed to students after watching videos of mathematical teaching in a 6-12 classroom, analyzing errors in authentic student work, and rehearsing and simulating teaching to peers.

\section{4.}

Teachers should have some understanding of the cultural relevance of the mathematics they learn and are called to teach. Ultimately, teachers are the greatest "advertisers/ sellers" of mathematics to future generations, and so they should be able to communicate the significance of mathematics in society in order to convey that significance to their students. Mathematics teacher educators should make sure to communicate how $\mathrm{K}-12$ mathematics is a quantitative language used to describe science, technology, and society. Mathematics teacher educators should be sure to communicate to all students, especially teachers, that many different cultures made and continue to make impactful contributions to mathematics by emphasizing contributions made by people from cultures that are underrepresented in mathematics to go beyond Eurocentric views of mathematical invention.

"Why is this important?" is a common question asked by students at all levels. Having mathematics teacher educators being able to communicate how various mathematical topics relate to our present and future world and demonstrate to students the usefulness of mathematics through application can help resolve such questions. Recently, there have been efforts to humanize/rehumanize mathematics and show that "mathematical thinking is influenced by a diversity of human environments and their elements, which include language, religion, mores, economics, social, and political activities" (Rosa \& Orey, 2016, p. 4). This focus on humanizing/rehumanizing mathematics is critical for those who have been marginalized as "schooling often creates structures, policies and rituals that convince people they are no longer mathematical" (Goffney \& Gutiérrez, 2018). Thus, when teaching teachers, mathematics teacher educators should communicate the importance and model inclusive practices that reduce barriers of access for all students.

In all my courses for teachers, I give historical information about the development of the mathematical topics of the course and show how many diverse people have contributed to mathematics. I also stress that many mathematical discoveries came out of a need to solve societal issues, which helps illustrate that mathematics is not a collection of abstract concepts that dropped out of the sky and that abstraction is a human innovation. Further, this helps dispel beliefs that mathematics is accessible only to certain people who are "smart enough to get it." Additionally, I stress the importance of metacognition (thinking about one's thinking) and process documentation in problem solving to value all mathematical thinking in class and not just traditional problem solving.

As a mathematician who is a mathematics teacher educator, I have the important task of not only helping teachers gain in-depth knowledge of mathematics but also helping to develop their Mathematical Knowledge for Teaching. As many teacher preparation programs teach pedagogy courses separate from the content courses, this can leave teachers with the complicated task of trying to merge these two knowledge bases (Ball, 2008). Therefore, to consolidate teachers' knowledge, instructors in both pedagogy and content courses need to work to enhance teachers' Mathematical Knowledge for Teaching.

Regardless of who our students are and what they major in, as mathematicians, familiarizing ourselves with 


\section{EDUCATION}

research-based, best instructional practices would benefit them all. Furthermore, mathematicians who teach teachers should continually strive to improve our own Mathematical Knowledge for Teaching Teachers to more effectively teach so that teachers have the potential to positively impact $\mathrm{K}-12$ student learning.

\section{References}

Association of Mathematics Teacher Educators. Standards for Preparing Teachers of Mathematics, 2017. Available online at amte.net/standards

Ball DL, Thames MH, Phelps G. Content knowledge for teaching: What makes it special?, Journal of Teacher Education, 59(5):389-407, 2008.

Bass H. Mathematicians as Educators, Notices Amer. Math. Soc., 44(1):18-21, 1997. Reprinted in Contemporary Issues in Mathematics Education.

Boaler J. Mathematical mindsets: unleashing students' potential through creative math, inspiring messages, and innovative teaching, John Wiley \& Sons: Hoboken, NJ, 2015.

Conference Board of the Mathematical Sciences. The Mathematical Education of Teachers II, Providence, RI, and Washington, DC: American Mathematical Society and Mathematical Association of America, 2012.

Elementary Math Project. Mathematical Knowledge for Teaching, https://elementarymathproject.com/emp_introdocs /mathematical-knowledge-for-teaching/(accessed August 14, 2019).

Goffney I, Gutiérrez R. Annual perspectives in mathematics education: Rehumanizing mathematics for Black, Indigenous, and Latinx students, Reston, VA: National Council of Teachers of Mathematics, 2018.

Grossman P, Hammerness K, McDonald M. Redefining teaching, re-imagining teacher education, Teachers and Teaching: theory and practice, (15):273-289, 2009.

Hart L, Oesterle S, Swars S. The Juxtaposition of Instructor and Student Perspectives on Mathematics Courses for Elementary Teachers, Educational Studies in Mathematics, (83):429-451, 2013.

Jaworski B, Huang R. Teachers and didacticians: key stakeholders in the processes of developing mathematics teaching, ZDM-The International Journal on Mathematics Education, 46(2):267-278, 2014.

Masingila J, Olanoff D, Kimani P. Mathematical knowledge for teaching teachers: knowledge used and developed by mathematics teacher educators in learning to teach via problem solving, Journal of Mathematics Teacher Education, 2017.

Mathematical Association of America Inc. The MAA Instructional Practices Guide, 2017, https://www.maa.org/sites /default/files/InstructPracGuide_web.pdf.

McDonald M, Kazemi E, Kavanagh SS. Core practices and pedagogies of teacher education: A call for a common language and collective activity, Journal of Teacher Education, 64(5):378-386, 2013.

National Council of Teachers of Mathematics. Principles To Actions: Ensuring Mathematical Success for All, Reston, VA, 2014.

Rosa M, Orey DC. Humanizing Mathematics through Ethnomodelling, Journal of Humanistic Mathematics, 6(2):3-22, 2016.
Sánchez M. A review of research trends in mathematics teacher education, PNA, (5):129-145, 2011.

Smith M, Stein M. 5 practices for orchestrating productive mathematics discussions, Reston, VA: National Council of Teachers of Mathematics, 2011.

Sullivan P, Wood T. Knowledge and beliefs in mathematics teaching and teaching development, Rotterdam, The Netherlands: Sense Publishers, 2008.

Superfine A, Welder R, Prasad P, Olanoff D, Eubanks-Turner C. Exploring Mathematical Knowledge for Teaching Teachers: Supporting Prospective Teachers' Relearning of Mathematics, The Math Enthusiast, forthcoming.

Zopf D. Mathematical Knowledge for Teaching Teachers: The Mathematical Work of and Knowledge Entailed by Teacher Education, 2010.

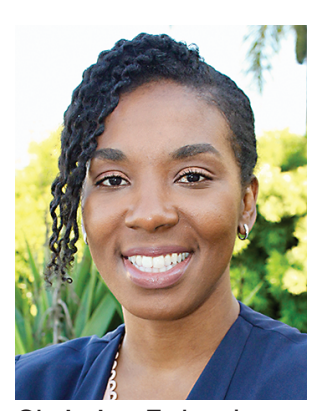

Christina Eubanks-

Turner

Credits

Author photo is by Amari Turner. 